\title{
Investigation of Dependent Variables on Utilizing Cotton Simulation Model
}

\author{
Abolfazl Biglar Beigi \\ Hamedan, Iran
}

\begin{abstract}
This research is focused on utilizing cotton simulation model (GOSSYM) to investigate the impact of different dependent variables such as different amount of Carbone Dioxide, rainfall, different Nitrogen Level, UV-B with or without irrigation, or different soil type in a MID-season cultivar for predicting and finding the influence of environmental factors on cotton yield, plant height, main stem nodes, and major phenological events such as squaring, flowering and boll opening during 30 years from 1964 to 1993 in Razan, Hamedan, Iran.
\end{abstract}

Keywords: Carbone Dioxide; phenological events; RegCM climate model ; Nitrogen level; MID-season

\section{INTRODUCTION}

Different variety of factors either climatic or inputs affect cotton productivity. There are various factors that influence cotton yield [1-2]. The actual daily solar radiation, maximum and minimum air temperatures, rainfall, and wind speed for 30 years (1964 to 1993) were used as current or ambient weather input scenarios for the model[3-6]. Changes in climate were calculated from results of a regional climate model (RegCM) nested within a General Circulation Model (GCM) from National Center for Atmospheric Research (NCAR) at Boulder, Colorado. The quantified changes in the future climate (i.e., maximum/minimum temperatures, solar radiation, precipitation, wind speed) were predicted using the RegCM climate model [7].

The weather input required to run GOSSYM is on a daily basis. Therefore, the projected monthly means for future weather parameters were used to create daily future weather files by modifying the daily current weather based on the assumption that changes in daily weather parameters will be constant for each month.[8-11] The monthly mean maximum and minimum temperature changes were added to and the ratios for the other three parameters (precipitation, solar radiation, and wind speed) were multiplied with the corresponding values of the daily 30-year current weather parameters to generate the daily future weather files for 30 years (future climate scenario). This methodology[12], however, retains the existing natural variability in the historic weather for the 30 years.

\section{METHODOLOGY}

In this research by applying the cotton simulation model, GOSSYM, all measurements was carried out. Data was recorded for 30 years and the model was written in Fortran to run the model and get the results. There were different scenarios, from MID- season cotton cultivar in rainfed or irrigated conditions, two different soil types (clay and loamy soil) and different planting dates and different Nitrogen level [12-14]. After running the model, data were collected in an excel file to do some statistics and plotting some graphs in order to investigate in more details. The results in the format of table and results is provided below.

\section{RESULTS AND DISCUSSION}

As it can be seen in Fig.1, Fig.2 and Fig.3 the slop for both graph is so small so, increasing co 2 don't affect corn height and maximum leaf area index and number of nodes in both irrigated or rainfed areas significantly, even fertilizer or water was supplied. There is a slightly decreasing, increasing for corn height and Maximum Leaf Area Index respectively but there is not a constant trend for number of nodes.

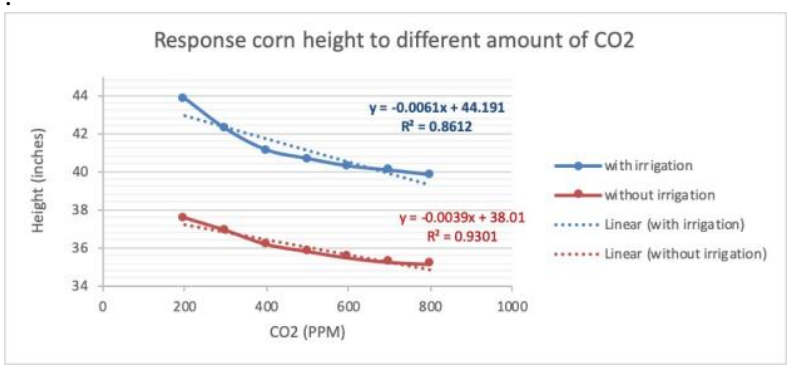

Figure 1. Response corn height to different amount of $\mathrm{CO} 2$ with and without irrigation over 30 years simulation period

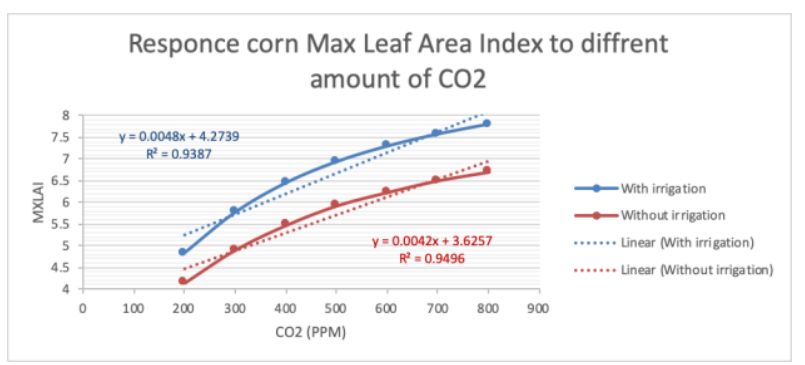

Figure 2. Response Corn Maximum Leaf Area Index to different amount of $\mathrm{CO} 2$ with and without irrigation over 30 years simulation period. 
Responce corn node to diffrent amount of $\mathrm{CO} 2$

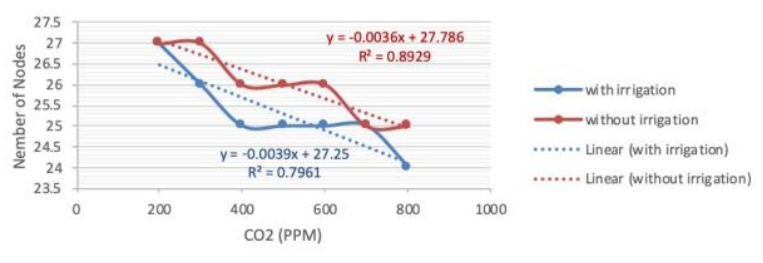

Figure 3. Response corn nodes to different amount of $\mathrm{CO} 2$ with and without irrigation over 30 years simulation period.

As it can be seen in Fig.1, Fig.2 and Fig.3 the slop for both graph is so small so, increasing co2 don't affect corn height and maximum leaf area index and number of nodes in both irrigated or rainfed areas significantly, even fertilizer or water was supplied. There is a slightly decreasing, increasing for corn height and Maximum Leaf Area Index respectively but there is not a constant trend for number of nodes

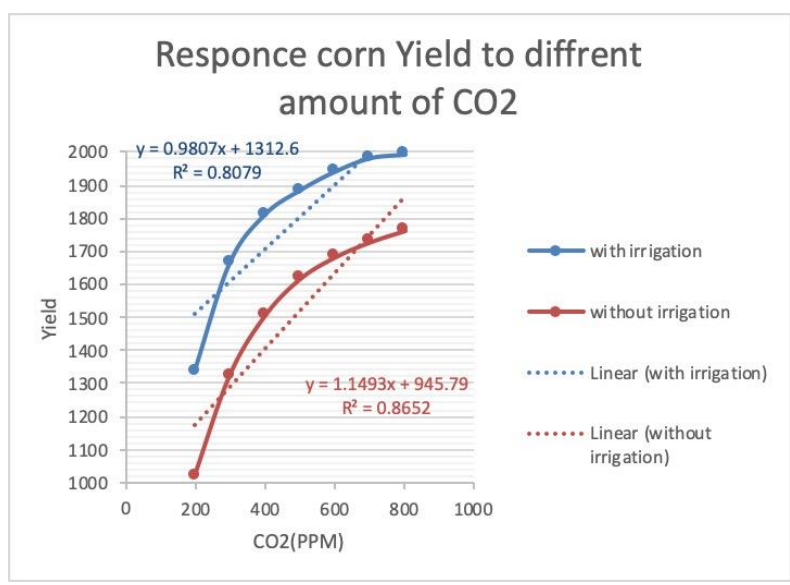

Figure 4. Response corn yield to different amount of $\mathrm{CO} 2$ with and without irrigation over 30 years simulation period.

As it can be seen in Fig.4, corn yield will be increased by increasing the amount of $\mathrm{co} 2$ and the yield in irrigated situation is more than rainfed and the importance of irrigation in increasing the yield was shown clearly.

Table 1. the impact of rainfall on different corn parameters under constant CO2 simulated over 30 years (1964 to 1993).

\begin{tabular}{|l|l|l|l|l|l|}
\hline $\begin{array}{l}\text { Rainfall } \\
\text { Factor }\end{array}$ & Height & MXLAI & Node & Yield & $\begin{array}{l}\text { DAE } \\
\text { FSQ }\end{array}$ \\
\hline 0.25 & 22.17 & 4.83 & 27 & 1336 & 27 \\
\hline 0.5 & 27.64 & 5.77 & 26 & 1665 & 27 \\
\hline 0.75 & 32.9 & 6.45 & 25 & 1812 & 27 \\
\hline 1 & 36.17 & 6.94 & 25 & 1886 & 27 \\
\hline 1.25 & 38.58 & 7.3 & 25 & 1943 & 27 \\
\hline
\end{tabular}

Rainfall in one of the important factor for researchers and farmer. It is not necessary to arrange irrigation by having the good amount precipitation on time.

As it can be seen in table.2, increasing rainfall does not have any effect on corn phenology processes which are be constant in 27, 49 and 89 days after emergence respectively for first square, first flower blossom and first open boll. there is not a constant trend for number of nodes also (Fig. 7).

Rainfall in one of the important factor for researchers and farmer. It is not necessary to arrange irrigation by having the good amount precipitation on time.

As it can be seen in table.2, increasing rainfall does not have any effect on corn phenology processes which are be constant in 27, 49 and 89 days after emergence respectively for first 
square, first flower blossom and first open boll. there is not a constant trend for number of nodes also (Fig. 7).

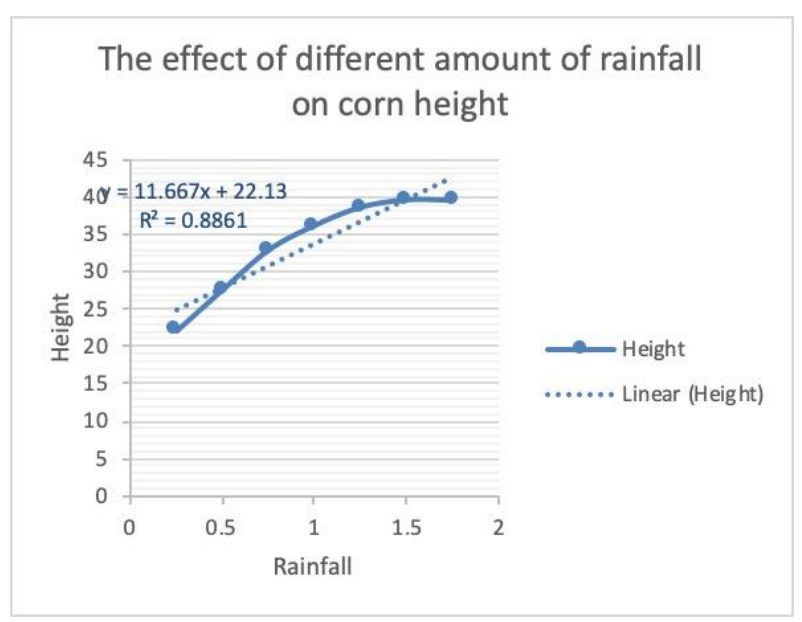

Figure 5. The effect of different amount of rainfall on corn height for 30 years.

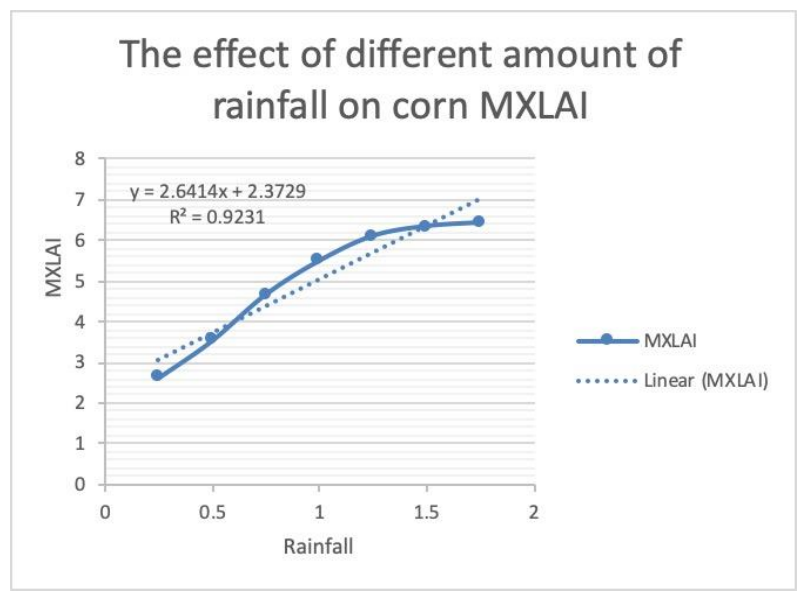

Figure 6. The effect of different amount of rainfall on corn MXLAI for 30 years.

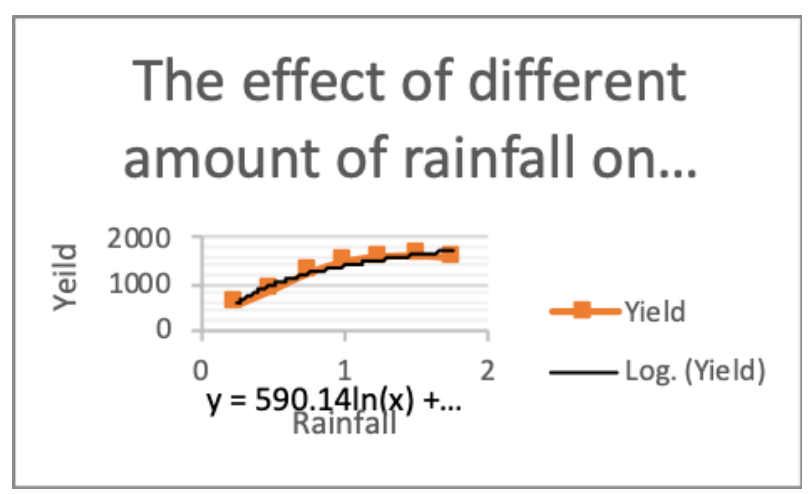

Figure 7. The effect of different amount of rainfall on yield for 30 years.

As it is shown in Fig. 5, Fig.6 and 7, by increasing rainfall, there is a increasing trend in corn height and max leaf area index. The increasing rainfall from 0.25 to 0.5 and 0.5 to 0.75 have more effect on yield rather than 1 to 1.25 and 1.25 to 0.5 .

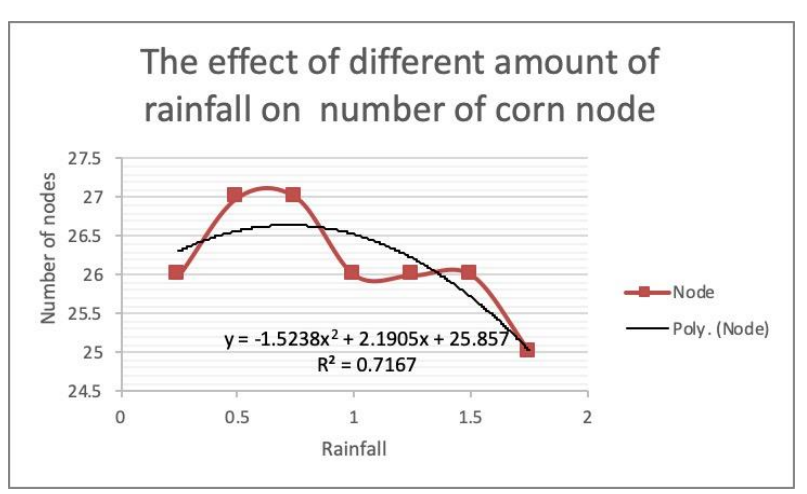

Figure 8 . The effect of different amount of rainfall on number of corn node.

\section{INFLUENCE OF NITROGEN ON CROP GROWTH AND YIELD UNDER TWO DIFFERENT SOIL TYPES}

Nitrogen is a critical factor for plants. And different soil types have different ability to keep fertilizers in themselves. Moreover, irrigation or rainfall have an important impact on keeping Nitrogen fertilizer in soil.

Table 3. Influence of nitrogen on crop growth and yield under two different soil types over a simulation period of 30 years

\begin{tabular}{|l|l|l|l|l|}
\hline $\begin{array}{l}\text { CO2 } \\
(\mathrm{ppm})\end{array}$ & Soil type & $\begin{array}{l}\text { Nitrogen } \\
\text { Level }\end{array}$ & Height & MXLAI \\
\hline 400 & 1 & 1 & 35.27 & 5.78 \\
\hline 400 & 1 & 2 & 37.62 & 6.18 \\
\hline 400 & 1 & 3 & 39.48 & 6.37 \\
\hline 400 & 1 & 4 & 41.1 & 6.45 \\
\hline 400 & 1 & 1 & 32.12 & 5.12 \\
\hline 400 & 1 & 2 & 33.61 & 5.39 \\
\hline 400 & 1 & 3 & 34.95 & 5.47 \\
\hline 400 & 1 & 4 & 36.17 & 5.48 \\
\hline 400 & 2 & 1 & 34.73 & 5.56 \\
\hline 400 & 2 & 2 & 37.44 & 6.01 \\
\hline
\end{tabular}




\begin{tabular}{|l|l|l|l|l|}
\hline 400 & 2 & 3 & 39.51 & 6.2 \\
\hline
\end{tabular}

This simulation investigates the influence of nitrogen in 4 different amount of nitrogen fertilizer $(50,100,150$ and $200 \mathrm{lbs}$ ) under 2 different soil types ( 1 for clay and 2 for loam) with and without irrigation.

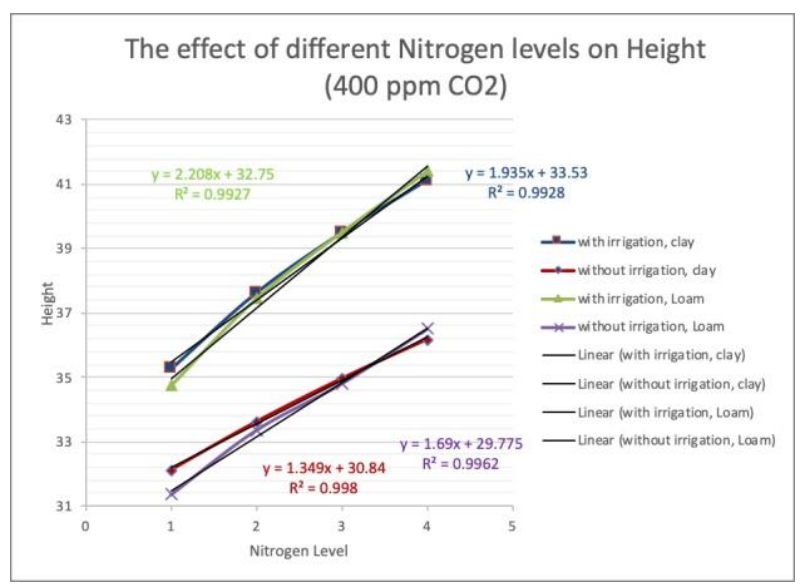

Figure 9 .The effect of different Nitrogen levels on Height (400 ppm CO2) over 30 years

As it can be seen in Fig. 9, increasing Nitrogen fertilizer cause to increase corn height but the impact in irrigated condition is more than rainfed condition. The irrigation condition has more effect than type of soil ( clay or loam)

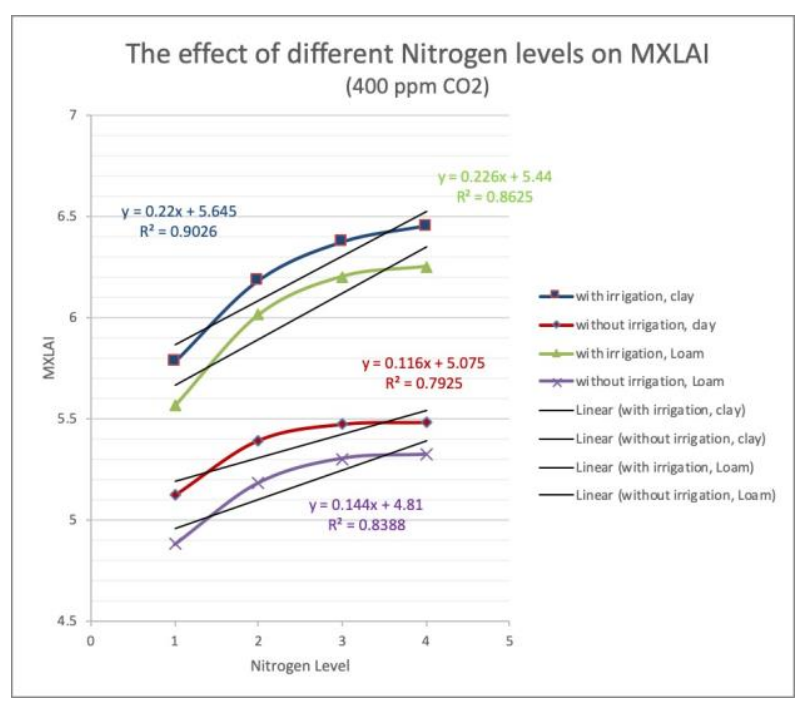

Figure 10 . - The effect of different Nitrogen levels on MXLAI (400 ppm CO2) over 30 years

As it can be seen in Fig. 10, increasing Nitrogen fertilizer cause to increase corn max leaf area index but the impact in irrigated condition is more than rainfed condition. The irrigation condition has more effect than type of soil (clay or loam) but the max leaf area index in clay soil is more than loamy soil. On both soil types maximum LAI remained at stable growth under irrigated conditions but reduced slightly under non- irrigated conditions for all amount of fertilizer $(\mathrm{N})$ applied.

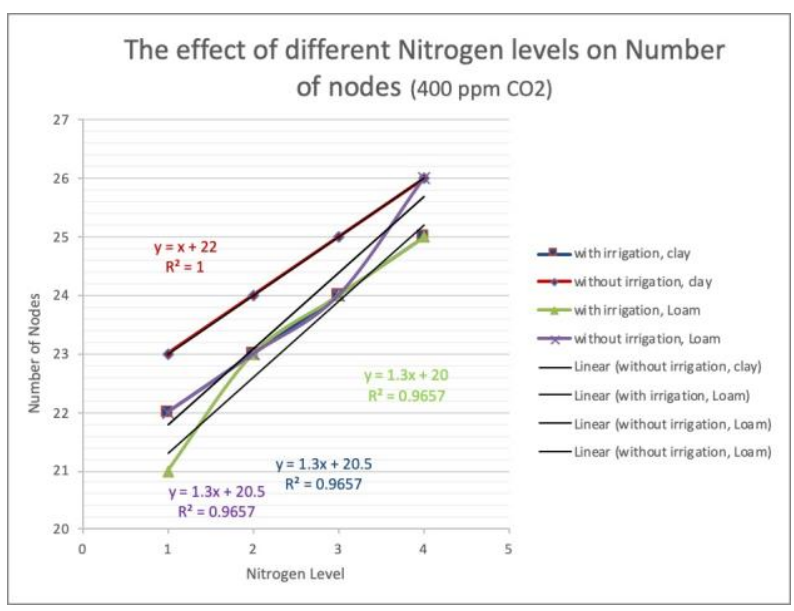

Figure 11 - The effect of different Nitrogen levels on MXLAI (400 ppm CO2) over 30 years

The number of nodes does not have any difference in clay soil with or without irrigation conditions. But by increasing the amount of nitrogen, the number of nodes increased in clay soil too. The difference is just when the type of soil change to loam.

\section{FUTURE WEATHER SCENARIOS WITH MITIGATION OPTIONS}

Plant growth and production can be affected by weather patterns together with other external factors. It can effect on plant phonological processes as well. Under current carbon dioxide conditions, cotton cultivar tends to be in high production, but it will be greatly affected by the future climate condition. In order to increase cotton production in a changing climate condition, one option probably is changing the planting dates.

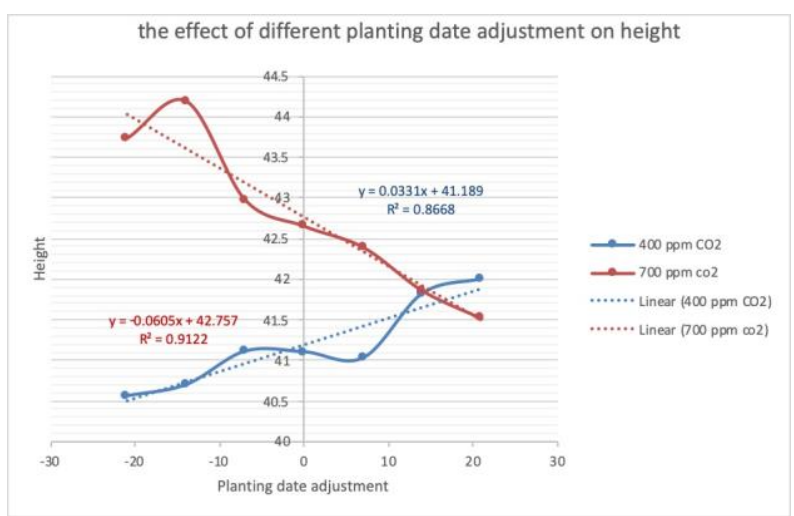


Base on the simulations, changing planting dates, $-21,-14$ and -7 days earlier than standard planting date, shows that plant growth remains constant under present CO2 level (400 PPM). But under future $\mathrm{CO} 2$ concentration, 700PPM, cotton plants are taller when planted at earlier planting dates but remains constant in height after planting at zero days and later. In addition, based on simulations, cotton cultivar had more LAI at future climate condition than plants grown at the current conditions. In future condition, in comparison to current condition, plants had more nodes when planted at earlier days.

Based on model predictions for cotton yield, over a 30 year on 700 ppm CO2 level, and adjusted planting date, yield will decrease as compare to the current condition, (700ppm CO2 concentration). Maximum decreased occurred at -21 earlier planting days at $37 \%$ and the least decreased at 21 days later plant date at $25 \%$. Changing scenarios and planting dates also have huge effects on cotton plant phenology, where first squaring, first flower bloom and first open boll will take place much earlier under future 700ppm CO2 concentration.

By increasing the planting date from -21 to 0 , days to first square, first flower blossom and first open boll will appear earlier. But it does not have any effect on 0 to +21 for to first square and first open boll.

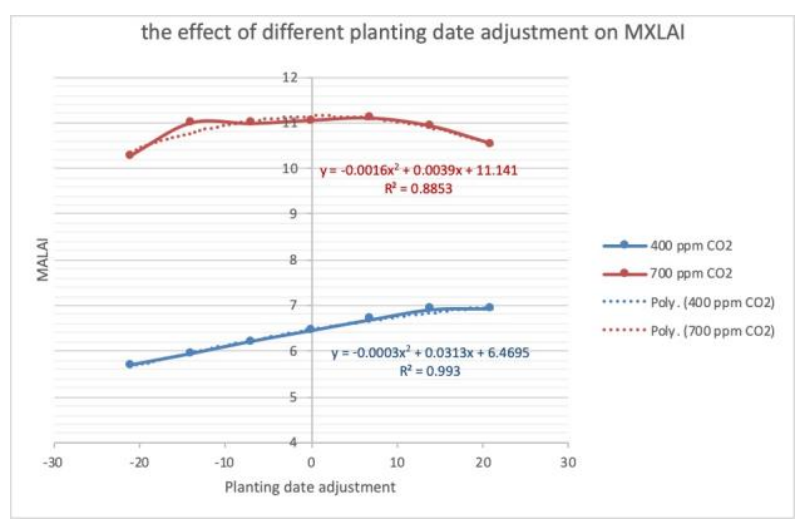

\section{CONCLUSION}

Cotton simulation model (GOSSYM), is a very important tool for researchers and farmers, especially during cotton growth which it can be easily affected by various factors. It is important to have proper management practices such as irrigation and fertilization program for cotton in order to gain maximum yields. By having some models like GOSSYM, farmers can notify that by every condition what they can do to avoid reduction in yield and growth or sometimes they know which factors effect on phenological processes.

\section{Acknowledgment}

Authors are very grateful to reviewers for carefully reading the paper and for their comments and suggestions which have improved the paper.

\section{REFERENCES}

[1] Ourang, Armin, SoheilPilehvar, MehrzadMortezaei, and Roya Damircheli. 2017 "Effect of aluminum doped iron oxide nanoparticles on magnetic properties of the polyacrylonitrile nanofibers." Journal of Polymer Engineering 37, no. 2 : 135-141..
[2] JALALI, ZOHREH, ASL VAHID HADDADI, Iman Shabani, Masoudsoleimani, Abbas Shafiee, And Roya Damircheli. 2014 "Improving Biocompatibility Of The Polyacrylonitlienanofibrous Scaffolds." .

[3] JALALI, ZOHREH, ASL VAHID HADDADI, Iman Shabani, Masoudsoleimani, And Roya Damircheli. 2014"A Novel Method For Producing Gelatin Nanofibers Contains Hydroxyapatite Nanoparticles." .

[4] Damircheli, Roya, Hamid Mirzadeh, Herish Moradi, Yasser Ghazizadeh, And Zohreh Jalali. 2014 "Electrospun Nanofibrous Scaffolds Based On Alginate For Skin Tissue Engineering."

[5] Damircheli, Roya, Hamid Mirzadeh, Herish Moradi, Yasser Ghazizadeh, And Zohreh Jalali. 2014"Electrospun Nanofibrous Scaffolds Based On Chitosan For Skin Tissue Engineering." .

[6] Pathak, Rohit, Razieh Barzin, And Ganesh C. Bora. 2018 "Data-Driven Precision Agricultural Applications Using Field Sensors And Unmanned Aerial Vehicle." International Journal of Precision Agricultural Aviation 1, No. 1.

[7] Barzin, Razieh, Amin Shirvani, and Hossein Lotfi. 2017 "Estimation of daily average downward shortwave radiation from MODIS data using principal components regression method: Fars province case study." International agrophysics 31, no. 1 : 23-34.

[8] A Sescu, L Taoudi, M Afsar, Iterative control of Görtler vortices via local wall deformations, Theoretical and Computational Fluid Dynamics 32 (1), 63-72

[9] A Sescu, L Taoudi, MZ Afsar, DS Thompson Control of Gortler vortices by means of staggered surface streaks, 46th AIAA Fluid Dynamics Conference, 3950

[10] Bastani, A. F., \& Damircheli, D. (2017). An adaptive algorithm for solving stochastic multi-point boundary value problems. Numerical Algorithms, 74(4), 11191143. 
International Journal of Science and Engineering Applications

Volume 10 Issue 01, 11-16, 2021, ISSN-2319-7560 (Online) 